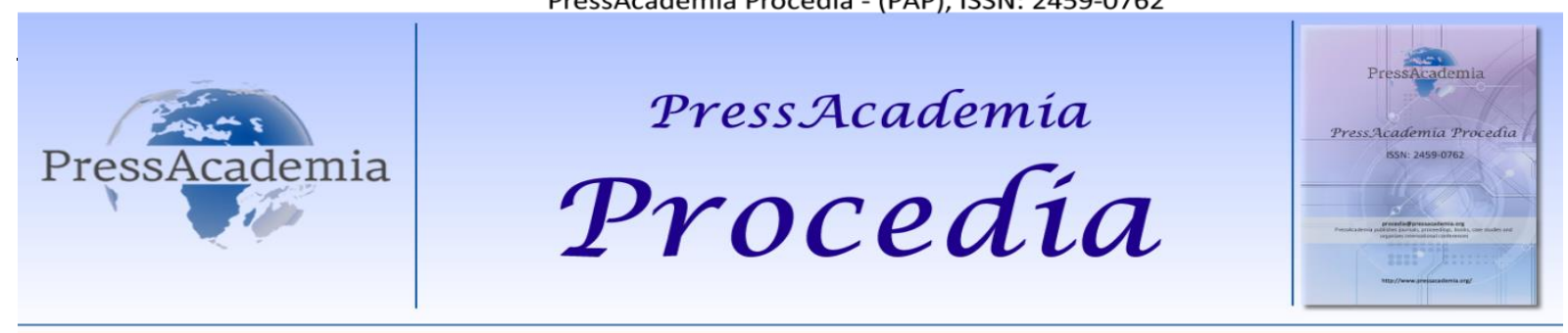

Global Business ResearchCongress (GBRC), May 24-25, 2017, Istanbul, Turkey.

\title{
A FIELD WORK TO DETERMINE EFFECTIVENESS OF CLOUD BASED ACCOUNTING ON ACCOUNTING PROFESSIONALS
}

\author{
DOI: 10.17261/Pressacademia.2017.397 \\ PAP-GBRC-V.3-2017(12)-p.104-117 \\ Ayşegül Ciger ${ }^{1}$, Bulent Kinay ${ }^{2}$ \\ ${ }^{1}$ Akdeniz Universitesi, Antalya, Türkiye. aysegulc@akdeniz.edu.tr \\ ${ }^{2}$ Akdeniz Üniversitesi, Antalya, Türkiye. bulentkinay@akdeniz.du.tr
}

\section{To cite this document}

Ciger, A. and B. Kinay, (2017). A field work to determine effectiveness of cloud based accounting on accounting professionals.

PressAcademia Procedia (PAP), V.3, p.104-117

Permemant link to this document: $\mathrm{http}: / /$ doi.org/10.17261/Pressacademia.2017.397

Copyright: Published by PressAcademia and limited licenced re-use rights only.

\begin{abstract}
The aim of the study is to measure the level of awareness and adoption of cloud-based accounting applications by accounting professionals (Certified Public Accountants) The survey method was chosen as the data collection method in the study. The questionnaire consists of questions about demographic information, professional information and reasons for choosing -or not choosing- web (cloud) based accounting program. The prepared questionnaire forms have been applied to accounting professionals operating in the central districts of Antalya. 297 questionnaires were selected according to analytical fit. Accountants using the web (cloud) based accounting program are young and middle age groups. The size of business and the type of book do not affect the use of the program. The most important reasons for choosing a web-based accounting program are the safekeeping and archiving of data, accessibility and automatic updates. The reasons for not being preferred are the lack of satisfaction/need from the current program and the lack of knowledge about cloud computing. Accounting professionals using the desktop accounting program do not have knowledge of cloud computing. Most importantly, accounting professionals using web-based accounting programs are also unaware that the program they use is cloud-based.
\end{abstract}

Keywords: Cloud computing, cloud based accounting, accounting profession, accounting professional, accounting Services.

JEL Codes: M41, M49, 033

\section{BULUT TABANLI MUHASEBE UYGULAMALARININ MESLEK MENSUPLARI ÜZERINDEKI ETKISINi BELIRLEMEYE YÖNELIK BIR ALAN ARAŞTIRMASI}

\section{ÖZET}

Çalışmanın amacı, meslek mensuplarının (Serbet Muhasebeci ve Mali Müşavir) bulut tabanlı muhasebe uygulamalarını benimseme düzeylerini ve farkındalıklarını ölçmektir. Çalışmada veri toplama yöntemi olarak anket yöntemi seçilmiştir. Anket formu demografik bilgiler, mesleki bilgiler ve web tabanlı muhasebe programını tercih etme ve etmeme nedenlerine yönelik sorulardan oluşmaktadır. Hazırlanan anket formları Antalya merkez ilçelerinde faaliyet gösteren Serbest Muhasebeci ve Mali Müşavirlere (SMMM) uygulanmıştır. 297 anket analize uygun seçilmiştir. Web (bulut) tabanlı muhasebe programı kullanan SMMM'ler genç ve orta yaş grubudur. Program kullanımını işletmenin büyüklüğü ve defter türü etkilememektedir. Web (bulut) tabanlı muhasebe programını tercih etme nedenlerinin en önemlileri, verilerin güvende tutulması ve arşivlenmesi, erişilebilirlik ve otomatik güncellemelerdir. Tercih etmeme nedenleri, mevcut programdan memnuniyet/ihtiyaç olmaması ve bulut bilişim ile ilgili bilgi sahibi olunmamasıdır. Masaüstü muhasebe programı kullanan SMMM'ler bulut bilişim ile ilgili bilgi sahibi değildir. En önemlisi de web tabanlı muhasebe programı kullanan SMMM'ler de kullandıkları programın bulut tabanlı olduğunun farkında değildir.

AnahtarKelimeler: Bulut bilişim, bulut tabanlı muhasebe, muhasebe mesleği, meslek mensupları, muhasebe hizmetleri. JEL Kodları: M41, M49, 033 


\section{GíRiş}

Son yıllarda, internetin ve bilgi teknolojisinin hızlı gelişimi, çeşitli teknolojiler için yenilikler sağlayarak, kullanııların kişisel, eğitim, iş, istihdam, eğlence, sağlık hizmetleri için web kaynaklarına erişme biçimini mümkün kılmıştır. Son 15 yılda, internet doğası, statik ortam Web 1.0'dan, yeni bir teknoloji dalgası olarak tanınmaya başlayan, kullanıcılarla etkileşimli ve dinamik bir ortam sunan Web 2.0'a geçmiştir (AlCattan, 2014:46; Du\&Cong, 2010:66). Diğer taraftan günümüzde mobil cihazlar da, web tarama ve diğer çevrimiçi etkinlikler için yaygın olarak kullanılan bir cihaz haline gelmiştir (Matthews, 2016). Bulut bilişim (BB) yaklaşımı, Web2.0, sanallaştırma, web hizmetleri vb. mevcut teknolojilere dayanan, iş dünyasında hızla büyüyen ve yeni bir iş modelinin ortaya çıkmasını sağlayan bir teknoloji olarak karşımıza çıkmaktadır. Aslında yıllardır BB olduğu bilinmeden kullanılan e-posta sistemleri, facebook, twitter gibi web uygulamaları BB uygulamalarıdır.

BB'nin literatürde genel kabul gören tanımı, Ulusal Standartlar ve Teknoloji Enstitüsü (NIST)'nün yaptığı tanımdır. Buna göre, BB, minimum yönetim çabası veya servis sağlayıcı etkileşimi ile hızla tedarik edilebilen ve serbest bırakılabilen, yapılandırılabilir bilgi işlem kaynaklarının (örneğin, ağlar, sunucular, depolama, uygulamalar ve servisler) ortak bir havuzdan her yerden, uygun, isteğe bağlı ağ erişimini sağlayan bir modeldir (Mell\&Grance, 2011). BB, kullanıcının internet aracıllı̆̆ ile yazılım uygulamalarına, donanıma, veriye ve işlem gücüne erişmesini sağlayan bir teknoloji olarak da tanımlanabilir.

BB zaman içinde değişmekle birlikte bir hizmet olarak altyapı (laaS), bir hizmet olarak platform (PaaS) ve bir hizmet olarak yazılım (SaaS) olmak üzere üç temel hizmet kategorisine ayrılmıştır(Techtarget Network, 2016). Kullanıcılar ana dağııım modelleri arasından özel bulut, genel bulut veya hibrit(melez) bulut seçimi yapabilir. Dağıtım modelinin seçimi büyük oranda teknik ve finansal fırsatlar ve risk çerçevesinde belirlenmektedir(Pazowski\&Pastuszak, 2013:861).

Gartner nc., 2020 yılına kadar bilgi teknolojileri (IT) harcamaları içinde buluta geçiş harcamalarının 1 trilyon Dolardan fazla olacağını (Stamford 2016); Uluslararası Veri Şirketi (IDC), 2020’ye kadar BB benimsemesinin çarpıcı bir şekilde gelişeceğini, Bain\&Company 'nin raporu da bulut IT pazarı gelirlerinin 390 milyar dolar ciroya ulaşacağını öngörmektedir (Brinda\&Heric, 2017)

Modern dünyanın zorluklarını ve beklentilerini karşılamaya çalışan kurumlar, rekabetçi ortamda çalışmak için etkili çözümler aramaktadırlar. IT araçları ve hizmetleri, işletmelerin verimli bir şekilde çalışması için vazgeçilmezdir (Geczy\&ızumi\&Hasida, 2012, s. 57). IT gelişmeleri, yönetimsel karar vermeyi geliştiren etkin ve verimli bilgi akışı sağlayarak işletmelerin kurumsal ve iş stratejisi hedeflerine ulaşma becerisini arttırmıştır. Bu da işletmenin hayatta kalma ihtimalini artırabilecektir (Lim, 2013:104). IT maliyetlerinde \% 80'lik bir azalışla BB hizmetlerinden en çok kazanç sağlayan işletmelerin küçük işletmeler olduğu belirtilmiştir. İşletmeler ilk yatırım maliyetlerinden daha çok operasyonel maliyetlerinde tasarruf sağlamaktadır (Fox,2012). Ancak BB'nin en önemli sorunu güvenlik ve gizlilik ihlalidir (Chou2015,73). BB tanındıkça, bilindikçe ve yaygınlaştıkça güvenlik endişesi de önemli düzeyde azalış göstermiştir (Göbel, 2015).

Muhasebe dünyasında da dönüşümü kaçınılmaz hale getireren BB, büyük veri, mobil teknoloji kullanımı ve sosyal ağ olarak belirlenen dört ana eğilim, muhasebecilerin iş yapma biçimlerini değiştirmeye başlamıştır (Borschowa, 2016). İ̧̧ dünyasında, muhasebe sistemlerinin BB'ye aktarılması yeni ve yenilikçi bir çözümdür. Nitekim birçok muhasebe yazılım firması ürünlerini buluta taşımıştır ve hızla da buluta geçişi devam etmektedir. Dünyada öne çıkan BB muhasebe yazılımları olarak; Financial Force.com, NetSuite, Microsoft Office 365, FreshBooks, Sivı, QuickBooks Online, Myob, Xero, Aqilla, Mint.com veya Waveaccounting sayılabilir (Dimitriu\&Matei, 2014:843). Müşteriler genelikle muhasebe modüllerinin tamamını tek bir tedarikçiden satın almak yerine farklı tedarikçilerden seçebilme ihtimaline sahiptirler (Randolph vd., 2016: xviii).

BB muhasebe uygulamaları ile veriler, hizmet sağlayıcı sunucularında saklanır ve bir web tarayıcısı üzerinden erişilebilir olur. BB kullanmak, muhasebecilerin tekrarlayan ve yönetime dayalı görevlerini azaltarak, danışmanlık rollerine odaklanmalarını sağlamaktadır. BB tabanlı programlar, muhasebecilerin artık müşterilerinin finansal verilerini bekleme zorunluluğunu ortadan kaldırdığı gibi müşterilerinin işlerini gerçek zamanlı olarak takip etme imkanı sunmaktadır (Huber, 2016; Angeles, 2017). Müşteriler, işletmelerinin nasıl performans gösterdiğini öğrenmek için muhasebecilerin portalına giriş yapabilmektedir (Blake, 2012). Tüm bu gelişmeler, muhasebecilerin maliyetlerini düşürürken, ücretlerini düşürmek zorunda kalmadan hizmetlerini iyileştirmelerine izin vermektedir (Kinsella, 2017).

BB'nin tercih edilmesinde ve benimsenmesinde öne çıkan özellikleri, erişilebilirlik, çok kullanıcılı olma, zaman ve maliyet tasarrufu, otomatik güncelleştirmeler, felaket kurtarma ve yedekleme yetenekleri, esneklik ve ölçeklenebilirlik ve daha iyi iş kararları olarak özetlenebilir (Gahlaut, 2016).

BB yeni gelişim sürecinde olduğu için avantajları olduğu kadar bir takım riskleri de taşımaktadır. En önemlileri, veri güvenliği ve gizliliği, kötü internet bağlantısı, kontrolün kullanıcıda olmaması ve hizmet sağlayıcıya bağımlılık, hizmetin kesintiye uğraması ve yasal düzenlemelerdir(Aytekin vd., 2016:12-13). Ayrıca muhasebecilerin işlerinde mobil cihazları yaygın bir şekilde kullanması potansiyel veri sızıntı noktalarını artırmaktadır (Sheinis\&Ference, 2014:16). 
Türkiye'de BB'nin her geçen gün daha iyi anlaşıldığı gözlemlenmekte, ancak kullanım oranı hala gelişmiş ülkelerin gerisinde kalmaktadır (Göbel, 2015). Kalkınma Bakanlığı'nın 2015-2018 eylem planında hazırlanan 5 senaryodan biri bulut bilişimin yaygınlaştırılmasıdır (Kalkınma Bakanlığı, 2014:18). BB hizmetlerine yönelik farkındalık eksikliği ve bu hizmetlerden yararlanmak isteyen KOBi'lerin mahremiyet, güvenlik gibi endişeleri, BB hizmetlerinin KOBi'lere yaygınlaşması önünde engel olarak görülmektedir (Kalkınma Bakanlığı, 2014:41). Diğer taraftan Business Software Alliance tarafından yapılan araştırmada, BB sıralamasında Türkiye, 24 ülke arasında 18. olarak değerlendirilmiştir. Türkiye'de veri koruma kanununun bulunmaması, internet suçları için cezaların caydırıcı nitelik taşımaması gibi nedenlerin bu sıralamada etkili olduğu belirtilmiştir (Busıness Software Allınce, 2013).

BB tabanlı muhasebe alanında yerli yazılımların (LUCA, t360, Patrofin, Dia, 1TÇ, Reeleezee, LOGO Bulut, MEP, vb) arttı̆̆ı görülmektedir. Bunun yanında yurtdışından yazılımlar (SAP, ZoHo) da az olmakla birlikte bir alternatif olarak bulunmaktadır (Öz, 2016:74). 2005 yılında kullanıma sunulan LUCA Projesi Türkiye Serbest Muhasebeci Mali Müşavirler ve Yeminli Mali Müşavirler Odaları Birliği-TÜRMOB ile Temel Eğitim ve Staj Merkezi TESMER tarafından geliştirilen Türkiye'nin ilk web tabanlı merkezi muhasebe sistemidir (Öz, 2016:74).

Meslek mensuplarının (Serbest Muhasebeci ve Mali Müşavir) bulut tabanlı muhasebe uygulamaları ile ilgili yaklaşımları ve benimseme düzeyleri üzerine çok az sayıda araştırma olup; Türkiye'de bu konu ile ilgili araştırma olmaması çalışmanın önemini artırmıştır.

Çalışmanın amacı, Serbest Serbest Muhasebeci ve Mali Müşavir'lerin (SMMM) bulut tabanlı muhasebe uygulamaları ile ilgili yaklaşımlarını ve tercihlerini ortaya koymaktır. Çalışma, SMMM'lerin teknolojik gelişmelere ne kadar kısa sürede uyum sağlayabildiklerini görme açısından önem taşımaktadır ve literatüre bu anlamda katkı sağlaması beklenmektedir.

\section{LITERATÜR INCELEMESI}

Çalışmanın amacı ve önemine uygun olarak seçilen çalışmalar Tablo 1'de özetlenmiştir.

Tablo 1: BB’nin Muhasebe Alanında Benimsenme Düzeyleri İle İlgili Yapılan Çalışmalar

\begin{tabular}{|c|c|c|c|}
\hline & Çalışma & Bulgular & Yöntem, Örnek \\
\hline \multirow{3}{*}{ 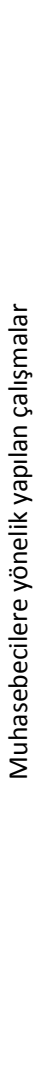 } & $\begin{array}{l}\text { Yiğitbaşıŏlu, } \\
2015\end{array}$ & $\begin{array}{l}\text { "Dış denetçilerin Avustralya'daki bulut bilgi işlemi benimseme düzeyleri” } \\
\text { adındaki çalışmada, birçok Avustralya organizasyonunda denetim } \\
\text { firmaları verilerin bilgi güvenliği ve gizlilik yönlerinden dolayı genel bulut } \\
\text { yerine özel ya da karma çözümleri tercih ettiği belirlenmiştir. Kritik } \\
\text { verileri içeren uygulamaların firmada veya özel bir kiralanmış sunucuda } \\
\text { tutulduğu, kritik olmayan kamu verileri denizaşırı bir yere taşınabileceği } \\
\text { tespit edilmiştir. BB hizmetlerini benimseme niyetlerini etkileyen, } \\
\text { örneğin IT maliyet yönetimi ve IT çevikliğindeki gelişmeler gibi çeşitli } \\
\text { avantajlar tespit edilmiştir. BB ile ilgili genel inancın aksine, görüşülen } \\
\text { kişiler için fiziksel veya ağ güvenliği temel bir endişe kaynağı olmadığı } \\
\text { ortaya çıkmıştır. Büyük kuruluşlar için KOBi'ler için olduğu gibi genel } \\
\text { buluta geçiş için eşit derecede büyük bir teşvik görülmemektedir. Halka } \\
\text { açık bulut bilgi işlem hizmetlerinin KOBi'ler için daha uygun olduğunu, } \\
\text { ancak hibrit bulutların büyük firmalar için daha uygun olduğu sonucuna } \\
\text { ulaşılmıştır. }\end{array}$ & $\begin{array}{l}\text { Nitel, } \\
\text { Avustralya'daki } 4 \text { büyük } \\
\text { muhasebe firmalarının } \\
\text { üçünde ve beş orta } \\
\text { kademe muhasebe } \\
\text { firması arasından } \\
9 \text { IT uzmanı ve } 6 \text { adli } \\
\text { muhasebe uzmanı. }\end{array}$ \\
\hline & $\begin{array}{l}\text { Tarmidia vd., } \\
2014\end{array}$ & $\begin{array}{l}\text { "Malezya'daki muhasebeciler arasındaki BB'nin bilinci ve benmsenmesi” } \\
\text { adlı araştırmada, muhasebeciler arasındaki BB'nin farkındalığı } \\
\text { ölçülmüştür. Çalışmada aynı zamanda bu yeni teknolojinin } \\
\text { (benimsenmemesinin) nedenlerini incelenmiştir. Katılımcıların üçte } \\
\text { ikisinin bu teknolojiyi tanımadığı ortaya çıkmıştır. Ankete katılanların } \\
\text { \%33'ü bulut bilgisine aşina olduklarını iddia ederken yine de kendilerini } \\
\text { bu konuda gerçekten bilgili bulmadıklarını, çoğunlukla iş nedeniyle } \\
\text { kullanmalarına rağmen, BB'nin normal yazılımlara kıyasla daha düşük } \\
\text { kazanma ve bakım maliyeti sağladığını belirtmişlerdir. }\end{array}$ & $\begin{array}{l}\text { Anket, } \\
\text { Malezya'da } 329 \\
\text { muhasebe firması. }\end{array}$ \\
\hline & $\begin{array}{l}\text { Cloud Accounting Institute, } \\
2014\end{array}$ & 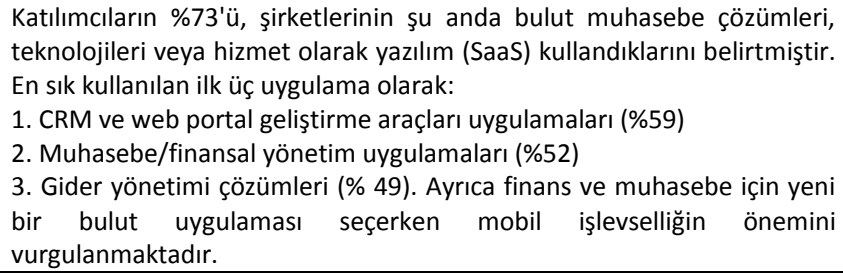 & $\begin{array}{l}\text { Anket, } \\
\text { ABD'de finans ve } \\
\text { muhasebe uzmanları }\end{array}$ \\
\hline
\end{tabular}




\begin{tabular}{|c|c|c|c|}
\hline & $\begin{array}{l}\text { Shkurti\&Muça, } \\
2014\end{array}$ & $\begin{array}{l}\text { “Arnavutukta muhasebe endüstrisi'nde BB'nin rolü ve analizi” adındaki } \\
\text { çalışmada, katılımcıların dörtte üçünden fazlası BB hakkında bilgiye sahip } \\
\text { olduklarını ve algılanan en büyük faydasının donanımda maliyet } \\
\text { tasarrufu olduğunu belirtmişlerdir. Ayrıca Muhasebecilerin ve } \\
\text { denetçilerin mesleki örgütleri, ilgili konular hakkında üyelerine eğitimler, } \\
\text { seminerler veya bilgilendirme toplantıları düzenlemek için daha fazla } \\
\text { gayret etmeleri gerektiği sonucuna ulaşmışlardır. }\end{array}$ & $\begin{array}{l}\text { Anket, } \\
\text { Arnavutlukta } 66 \\
\text { muhasebeci ve denetçi }\end{array}$ \\
\hline & $\begin{array}{l}\text { Defelice, } \\
2010\end{array}$ & $\begin{array}{l}\text { Yaklaşık } 10 \text { yıl içinde geleneksel modele dayalı hiçbir yazılım } \\
\text { uygulamasının olmayacağı yönünde görüşler bulunmakta olup, } \\
\text { katılımcıların \% 70'inin web tabanlı uygulamaları } 6 \text { ile } 18 \text { ay içinde } \\
\text { artırmayı planladıkları tespit edilmiştir. }\end{array}$ & $\begin{array}{l}\text { Anket, } \\
\text { AICPA'nın pazarlama kolu } \\
\text { olan CPA2Biz tarafından } \\
1000 \text { 'den fazla muhasebe } \\
\text { firması. }\end{array}$ \\
\hline \multirow{3}{*}{ 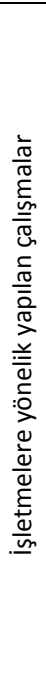 } & $\begin{array}{l}\mathrm{CCH} \\
\text { Business, } \\
2013\end{array}$ & $\begin{array}{l}\text { KOBI'lerin \%14'ü muhasebe işlemleri için web tabanlı muhasebe } \\
\text { yazılımları kullanmakta ve } 18 \text { ile } 34 \text { yaş arasındaki KOBi } \\
\text { sahipleri/yöneticilerinin, web tabanlı muhasebe yazılımları kullanmayı } \\
\text { daha çok tercih ettikleri ortaya çıkmıştır. Muhasebecilerin ise \% } 23^{\prime} \text { ü } \\
\text { web tabanlı muhasebe yazılımı kullanırken } 18 \text { ile } 34 \text { yaş arasındaki } \\
\text { muhasebecilerin de bulut tabanlı yazılımları daha çok tercih ettikleri } \\
\text { belirlenmiştir. Muhasebeciler web tabanlı bir sistem kullanmanın en } \\
\text { büyük faydasının her yerden erişilebilirlilik olduğunu; bazı } \\
\text { muhasebeciler, bu sistemi kullanmamalarının en önemli temel nedenleri } \\
\text { olarak yalnızca bir çalışma sistemine (\% } 37) \text { sahip olma ve güvenlik } \\
\text { endişesi olarak belirtmişlerdir. }\end{array}$ & $\begin{array}{l}\text { Anket, } \\
\text { Avustralya'da } 1.018 \\
\text { işletme sahibi ve } 212 \\
\text { Muhasebe firması. }\end{array}$ \\
\hline & $\begin{array}{l}\text { Strauss vd., } \\
2016\end{array}$ & $\begin{array}{l}\text { “BB’nin yönetim muhasebesi ve karar verme üzerine etkileri” adındaki } \\
\text { çalışmada; KOBI'lerin bulut teknolojisini benimseme ve maliyet tasarrufu } \\
\text { olasılığının daha yüksek olduğu tespit edilmiştir. }\end{array}$ & $\begin{array}{lr}\begin{array}{l}\text { Anket, } \\
\text { Almanya'da }\end{array} & \text { farklı } \\
\text { sektörde } & \text { faaliyet } \\
\text { gösteren } & 139 \quad \text { Kobi } \\
\text { işletmesi. } & \end{array}$ \\
\hline & $\begin{array}{l}\text { Gupta vd., } \\
2013\end{array}$ & $\begin{array}{l}\text { Bu araştırmada, kullanım kolaylığı ve rahatlık, KOBI'lerin BB'yi } \\
\text { benimsemelerinde en önemli faktör olarak belirlenmiştir. İkinci faktör, } \\
\text { geliştirilmiş güvenlik ve gizliliktir. BB kullanılması ve benimsenmesindeki } \\
\text { üçüncü faktör ise maliyeti azaltmasıdır. }\end{array}$ & $\begin{array}{l}\text { Anket, } \\
\text { Singapur, Malezya ve } \\
\text { Hindistan'da } 211 \text { Kobi / } \\
\text { küçük ölçekli işletme. }\end{array}$ \\
\hline
\end{tabular}

Muhasebeciler ve işletme yöneticilerine BB'nin benimesenmesi ile ilgili farklı ülkelerde yapılan çeşitli çalışmalarda, ülkeler arasında benimsenme düzeylerinde önemli bir farkın olmadığı görülmüştür. Ancak CCH (2013) çalışmasında kullanıcılarının yaş durumunun BB'nin benimsenmesinde etkili olduğunu ortaya koymuştur. Diğer taraftan finans ve muhasebe için yeni bir bulut uygulaması seçerken mobil işlevselliğin önemini de vurgulamaktadır. Benimsenme düzeyleri ile ilgili yapılan çalışmaların ortak sonuçlarında BB'nin öne çıkan avantajları; erişebilirlilik, maliyet yönetimi, çabukluk, kullanım kolaylığı ve rahatlık ve geliştirilmiş güvenlik ve gizlilik iken, riskler ise; güvenlik endişesi ve BB'nin tanınmaması olarak tespit edilmiştir. Yiğitbaşoğlu (2015) yaptığı çalışmada güvenliğin temel bir endişe kaynağı olmadığı sonucunu ortaya çıkarmıştır. Denetim şirketlerinin bilgi güvenliği ve gizliliğini artırmak için özel ya da hibrid dağıtım modelini tercih ettiklerini belirtmiştir. Yapılan çalışmaların sonucu olarak muhasebeci ve işletme yöneticilerinin BB' yi benimseme düzeylerinin yüksek olduğu söylenebilir.

\section{VERI VE YÖNTEM}

Çalışmada veri toplama yöntemi olarak anket yöntemi seçilmiştir. Anket soruları literatür incelemesinde yer alan kaynaklardaki araştırmalar değerlendirilerek oluşturulmuştur. Anket üç bölümden oluşmaktadır. Birinci bölümde demografik özellikler, ikinci bölümde mesleki bilgiler ve üçüncü bölümde web tabanlı (bulut) muhasebe programı ve mobil uygulamaları kullanma ve benimse düzeyleri ile ilgili sorular yer almaktadır. Çalışmada anakütleyi Antalya merkez ilçelerde faaliyet gösteren Serbest Muhasebeci ve Mali Müşavirler(SMMM) oluşturmaktadır. 2016 yılı itibariyle Antalya Serbest Muhasebeci ve Mali Müşavirler odasına kayıtlı toplam 1431 SMMMolup, bunun 1176'sı merkez ilçelerdebulunmaktadır (ASMO, 2017).Çalışmada yüz yüze görüşme yapılarak 150 adet ve 200 adet anket formu da SMMM'lere dağıtılmak üzere toplam 350 adet anket formu kullanılmıştır. Anketin SMMM'lerin yoğun çalışma dönemine (vergi hesaplama, beyanname hazırlama vb.) tesadüf etmesinden dolayı dağıtılan anketlerden 30 adeti cevaplandırılamamıştır. Ayrıca 23 adet anket formu da geçersiz sayılarak toplam 297 adet anket formu analize uygun bulunmuştur.

\section{BULGULAR VE TARTIŞMA}

SMMM'lerin Bulut tabanlı muhasebe programını benimseme düzeylerini belirlemenin amaçlandığı bu çalışmada elde edilen veriler frekans dağılımı, ki-kare ve t-testi gibi betimsel yöntemlerle değerlendirilmiştir. Bu bölüm, elde edilen bulgular ve bu bulgularayönelik tartışmaları içermektedir. 
Ankete katılan SMMM'lerin demografik ve mesleki bilgileri Tablo 2'de yer almaktadır.

Tablo 2: Demografik ve Mesleki Bilgiler

\begin{tabular}{|c|c|c|c|}
\hline & & $\mathrm{n}$ & $\%$ \\
\hline \multirow{2}{*}{ Cinsiyet } & Kadın & 71 & 23,9 \\
\hline & Erkek & 226 & 76,1 \\
\hline \multirow{3}{*}{ Yaş } & $24-34$ yaş & 75 & 25,3 \\
\hline & $35-44$ yaş & 128 & 43,2 \\
\hline & 45 yaş ve üzeri & 93 & 31,4 \\
\hline \multirow{3}{*}{ Eğitim Durumu } & Lisans & 240 & 85,7 \\
\hline & Yükseklisans & 39 & 13,9 \\
\hline & Doktora & 1 & 4 \\
\hline \multirow{3}{*}{ Mesleki Faaliyet Süresi } & 10 yıl ve altı & 131 & 44,7 \\
\hline & $11-15$ yıl & 68 & 23,2 \\
\hline & 16 yıl ve üzeri & 94 & 32,1 \\
\hline \multirow{4}{*}{ Çalışan Sayısı } & 0 kişi & 90 & 30,4 \\
\hline & 1 kişi & 81 & 27,4 \\
\hline & 2 kişi & 73 & 24,7 \\
\hline & 3 kişi ve üzeri & 52 & 13,5 \\
\hline \multicolumn{4}{|c|}{ Tutulan Defterlerin Türlerine Göre Oranı } \\
\hline \multirow{5}{*}{ Basit Usul Defter Oranı } & $0-\% 20$ & 136 & 81,9 \\
\hline & $\% 21-40$ & 16 & 9,6 \\
\hline & $\% 41-60$ & 8 & 4,8 \\
\hline & $\% 61-80$ & 5 & 3,0 \\
\hline & $\% 81-100$ & 1 & 6 \\
\hline \multirow{5}{*}{ İşletme Esası Defter Oranı } & $0-\% 20$ & 36 & 12,8 \\
\hline & $\% 21-40$ & 104 & 37,0 \\
\hline & $\% 41-60$ & 86 & 30,6 \\
\hline & $\% 61-80$ & 44 & 15,7 \\
\hline & $\% 81-100$ & 11 & 3,9 \\
\hline \multirow{5}{*}{ Bilanço Esası Defter Oranı } & $0-\% 20$ & 53 & 18,6 \\
\hline & $\% 21-40$ & 64 & 22,5 \\
\hline & $\% 41-60$ & 88 & 30,9 \\
\hline & $\% 61-80$ & 46 & 16,1 \\
\hline & $\% 81-100$ & 34 & 11,9 \\
\hline \multicolumn{4}{|c|}{$\begin{array}{l}\text { Bilanço Esasına Göre Tutulan } \\
\text { Defterlerin İşletme Büyüklüklerine } \\
\text { Göre Oranı }\end{array}$} \\
\hline
\end{tabular}




\begin{tabular}{lccc}
\hline & $0-\% 20$ & 94 & 34,3 \\
Mikro Ölçekli İsletme Defter Oranı & $\% 21-40$ & 46 & 16,8 \\
& $\% 41-60$ & 32 & 11,7 \\
& $\% 61-80$ & 61 & 22,3 \\
& $\% 81-100$ & 41 & 15,0 \\
\hline Küçük Ölçekli işletme Defter Oranı & $0-\% 20$ & 103 & 44,4 \\
& $\% 21-40$ & 37 & 15,9 \\
& $\% 41-60$ & 47 & 20,3 \\
Orta Ölçekli işletme Defter Oranı & $\% 61-80$ & 18 & 7,8 \\
& $\% 81-100$ & 27 & 11,6 \\
\hline & $0-\% 20$ & 102 & 55,7 \\
& $\% 21-40$ & 35 & 19,1 \\
& $\% 41-60$ & 9 & 4,9 \\
& $\% 81-80$ & 4 & 2,2 \\
\hline
\end{tabular}

Ankete katılan SMMM'lerin \%23,9'u kadın, \%76,1'i erkek meslek mensubudur. 24-34 yaş arası olanların oranı \%25,3; 35-44 yaş arası olanların oranı \%43,2; 45 yaş ve üzeri olanların oranı $\% 31,4$ 'tür. Lisans mezunu olanların oranı $\% 85,7$ 'dir. Katılımcılardan mesleki faaliyet süresi 10 yıl ve altı olanların oranı \%44,7'dir. SMMM'lerin tuttukları defterler içinde basit usul defter oranı 0-\%20 arası olanların oranı \%81,9, işletme esası defter oranı \%21-40 arası olanların oranı \%37,0; bilanço esası defter oranı \%41-60 arası olanların oranı \%30,9'dur. SMMM'lerin bilanço esasına göre tuttukları defterler içinde mikro ölçekli işletme defter oranı 0-\%20 arası olanların oranı \%34,3, küçük ölçekli işletme defter oranı 0-\%20 arası olanların oranı $\% 44,4$; orta ölçekli işletme defter oranı 0-\%20 arası olanların oranı \%55,7'dir.

Ankete katılan SMMM'lerin kullandıkları muhasebe programı türü, adı, kullanma süresi ve genel olarak mükelleflerinin kullandıkları muhasebe program bilgileri Tablo 3'te verilmektedir.

Tablo 3: SMMM ve Mükelleflerinin Kullandıkları Muhasebe Programı İle İlgili Bilgileri

\begin{tabular}{llrr}
\hline & & $n$ & $\%$ \\
\hline \multirow{2}{*}{ Kullandığı Muhasebe Programı } & Masaüstü Uygulama & 111 & 37,6 \\
& Web Tabanlı Uygulama & 184 & 62,4 \\
\hline & Eta & 20 & 9,9 \\
Kullandığı Program Adı & Logo & 132 & 65,0 \\
& Zirve & 6 & 3,0 \\
& Mikro & 23 & 11,3 \\
& Link-Datasoft & 15 & 7,4 \\
Mevcut Programı Kullanma Süresi & 4 yıl ve altı & 7 & 3,4 \\
\hline \multirow{2}{*}{ Çoğunlukla Mükellefin Kullandığı Program } & 5-7 yıl & 94 & 32,1 \\
& 8-11 yıl & 100 & 34,1 \\
& Web Tabanlı Uygulama & 51 & 17,4 \\
& 11 yıl ve üzeri & 49 & 16,4 \\
\hline
\end{tabular}


Masaüstü uygulama tabanlı muhasebe programı kullanan SMMM'lerin oranı \%37,6 iken web tabanlı muhasebe programı kullananların oranı \%62,4; LUCA programını kullananların oranı ise \%65'tir. Web tabanlı muhasebe programı kullanan SMMM'lerin kullandıkları tek programın LUCA olması dikkat çekici bir bulgudur. Katılımcıların yarsından fazlası mevcut programlarını 0-7 yıl arasında kullanmaktadır. Mükelleflerinin yaklaşık \%67'si ise masaüstü muhasebe programı kullanmaktadır.

Tablo 4: Web Tabanlı (Bulut) Muhasebe Programı Kullanma Tercihi

\begin{tabular}{|c|c|c|c|}
\hline & & $\mathrm{n}$ & $\%$ \\
\hline \multirow{2}{*}{$\begin{array}{l}\text { Gelecek } 3 \text { Yıl İçinde Web Tabanlı } \\
\text { Muhasebe Programı Kullanma Planı }\end{array}$} & Evet & 93 & 39,6 \\
\hline & Hayır & 142 & 60,4 \\
\hline \multirow{2}{*}{$\begin{array}{l}\text { Mükellef Web Tabanlı Muhasebe } \\
\text { Programı Kullanmasını İsterse }\end{array}$} & Tavsiyesine Uyarım & 157 & 64,1 \\
\hline & Defterini Tutmayı Bırakııım & 88 & 35,9 \\
\hline
\end{tabular}

Ankete katılan SMMM'lerin \%60,4'ü gelecek 3 yıl içinde web tabanlı muhasebe programı kullanmayı düşünmemektedir. Mükelleflerinin istemesi durumunda bulut tabanlı muhasebe programı kullanmayı düşünenlerin oranı \%64,1'dir.

SMMM'lerin kullandıkları muhasebe programı ile demografik ve mesleki bilgileri arasındaki ilişki analizleri Tablo 5,6,7,8 ve 9'da yer almaktadır. Cinsiyet ve çalışan sayısı çalışmanın amacı ile ilgili olmadığı için, eğitim durumu da katılımcıların neredeyse tamamı lisans mezunu olduğu için analizi yapılmamıştır.

Tablo 5: Kullanılan Muhasebe Programı ile Yaş Arasındaki iliş̧ki

\begin{tabular}{|c|c|c|c|c|c|c|}
\hline & & & \multicolumn{2}{|c|}{ Kullanılan Muhasebe Programı } & \multirow[b]{2}{*}{ Ki-Kare } & \multirow[b]{2}{*}{$\mathrm{P}$} \\
\hline & & & Masaüstü Uygulama & $\begin{array}{c}\text { Web Tabanlı } \\
\text { Uygulama }\end{array}$ & & \\
\hline \multirow{6}{*}{ Yaş } & & $\mathrm{n}$ & 29 & 45 & \multirow{6}{*}{4,001} & \multirow{6}{*}{ 135 } \\
\hline & 24-s4 yaş & $\%$ & 26,4 & 24,6 & & \\
\hline & & $\mathrm{n}$ & 40 & 87 & & \\
\hline & 35-44 yaş & $\%$ & 36,4 & 47,5 & & \\
\hline & \multirow{2}{*}{45 yaş ve üzeri } & $\mathrm{n}$ & 41 & 51 & & \\
\hline & & $\%$ & 37,3 & 27,9 & & \\
\hline
\end{tabular}

Yapılan ki-kare analizine göre kullanılan muhasebe programı ile yaş arasında ilişki bulunmamaktadır ( $p>0,05)$. Ancak tablo incelendiğinde web tabanlı muhasebe programını kullanmayı tercih eden SMMM'lerin genç ve orta yaşta yoğunlaştığı görülmektedir.

Tablo 6: Kullanılan Muhasebe Programı ile Mesleki Faaliyet Süresi Arasındaki iliş̧ki

\begin{tabular}{|c|c|c|c|c|c|c|}
\hline & & & \multicolumn{2}{|c|}{ Kullanılan Muhasebe Programı } & \multirow[b]{2}{*}{ Ki-kare } & \multirow[b]{2}{*}{$\mathrm{p}$} \\
\hline & & & Masaüstü Uygulama & $\begin{array}{c}\text { Web Tabanlı } \\
\text { Uygulama }\end{array}$ & & \\
\hline \multirow{6}{*}{ Mesleki Faaliyet Süresi } & \multirow{2}{*}{10 yıl ve altı } & $\mathrm{N}$ & 52 & 77 & \multirow{6}{*}{6,166} & \multirow{6}{*}{,046 } \\
\hline & & $\%$ & 47,7 & 42,5 & & \\
\hline & \multirow{2}{*}{$11-15$ yll } & $\mathrm{N}$ & 17 & 51 & & \\
\hline & & $\%$ & 15,6 & 28,2 & & \\
\hline & \multirow{2}{*}{16 yıl ve üzeri } & $\mathrm{N}$ & 40 & 53 & & \\
\hline & & $\%$ & 36,7 & 29,3 & & \\
\hline
\end{tabular}

Tablo 6’ya göre muhasebe programı ile mesleki faaliyet süresi arasında ilişki bulunmaktadır $(p<0,05)$. Buna göre masaüstü uygulama tabanlı muhasebe programını kullananların çoğunluğunun $(\% 47,7)$ ve web tabanlı muhasebe programını kullananların çoğunluğunun $(\% 42,5)$ mesleki süreleri 10 yıl ve altıdır. Mesleki faaliyet sürelerine göre web tabanlı muhasebe 
programı kullananların önemli bir oranı 0-15 yı aralığındadır. Bu da genç ve orta yaş grubunda tercih edilme durumunu desteklemektedir.

Tablo 7: Kullanılan Muhasebe Programı ile Mevcut Programın Kullanılma Süresi Arasındaki İlişki

\begin{tabular}{|c|c|c|c|c|c|c|}
\hline & & & \multicolumn{2}{|c|}{ Kullanılan Muhasebe Programı } & \multirow[b]{2}{*}{ Ki-kare } & \multirow[b]{2}{*}{$p$} \\
\hline & & & $\begin{array}{l}\text { Masaüstü } \\
\text { uygulama }\end{array}$ & $\begin{array}{l}\text { Web Tabanlı } \\
\text { Uygulama }\end{array}$ & & \\
\hline \multirow{8}{*}{$\begin{array}{l}\text { Mevcut Programı Kullanım } \\
\text { Süresi }\end{array}$} & \multirow{2}{*}{4 yıl ve altı } & $\mathrm{N}$ & 26 & 67 & \multirow{8}{*}{10,663} & \multirow{8}{*}{,014 } \\
\hline & & $\%$ & 23,6 & 37,2 & & \\
\hline & \multirow{2}{*}{$5-7 \mathrm{yıl}$} & $\mathrm{N}$ & 35 & 64 & & \\
\hline & & $\%$ & 31,8 & 35,6 & & \\
\hline & \multirow{2}{*}{ 8-11 yıl } & $\mathrm{N}$ & 24 & 27 & & \\
\hline & & $\%$ & $21,8 \%$ & $15,0 \%$ & & \\
\hline & \multirow{2}{*}{11 yıl ve üzeri } & $\mathrm{N}$ & 25 & 22 & & \\
\hline & & $\%$ & 22,7 & 12,2 & & \\
\hline
\end{tabular}

Kullanılan muhasebe programı ile mevcut programın kullanılma süresi arasında ilişki bulunmaktadır $(p<0,05)$. Masaüstü uygulama tabanlı muhasebe programını kullananların \%31,8'i mevcut programı kullanma süresi 5-7 yıl aralığında iken web tabanlı muhasebe programını kullananların \%37,2'si 4 yıl ve altıdır.

Tablo 8: Kullanılan Muhasebe Programı ile Tutulan Defter Türlerine Göre Oranı Arasındaki Ilişki

\begin{tabular}{|c|c|c|c|c|c|c|}
\hline & & & \multicolumn{2}{|c|}{ Kullanılan Muhasebe Programı } & \multirow[b]{2}{*}{ Ki-kare } & \multirow[b]{2}{*}{$\mathrm{p}$} \\
\hline & & & Masaüstü uygulama & $\begin{array}{c}\text { Web Tabanlı } \\
\text { Uygulama }\end{array}$ & & \\
\hline \multirow{6}{*}{ Basit Usul Defter Oranı } & \multirow{2}{*}{$0-\% 20$} & $\mathrm{n}$ & 52 & 83 & \multirow{6}{*}{7,385} & \multirow{6}{*}{, 025} \\
\hline & & $\%$ & 78,8 & 83,8 & & \\
\hline & & $\mathrm{n}$ & 4 & 12 & & \\
\hline & $10<1-40$ & $\%$ & 6,1 & 12,1 & & \\
\hline & \multirow{2}{*}{$\% 41$ ve üzeri } & $\mathrm{n}$ & 10 & 4 & & \\
\hline & & $\%$ & 15,2 & 4,0 & & \\
\hline \multirow{6}{*}{ İşletme Esası Defter Oranı } & \multirow{2}{*}{$0-\% 20$} & $\mathrm{~N}$ & 15 & 21 & \multirow{6}{*}{1,425} & \multirow{6}{*}{490} \\
\hline & & $\%$ & 14,2 & 12,2 & & \\
\hline & & $\mathrm{N}$ & 35 & 69 & & \\
\hline & $10<1-40$ & $\%$ & 33,0 & 40,1 & & \\
\hline & \multirow{2}{*}{$\% 41$ ve üzeri } & $\mathrm{N}$ & 56 & 82 & & \\
\hline & & $\%$ & 52,8 & 47,7 & & \\
\hline \multirow{6}{*}{ Bilanço Esası Defter Oranı } & \multirow{2}{*}{$0-\% 20$} & $\mathrm{n}$ & 17 & 35 & \multirow{6}{*}{0,545} & \multirow{6}{*}{ 761 } \\
\hline & & $\%$ & 16,3 & 19,7 & & \\
\hline & $\% 21-40$ & $\mathrm{n}$ & 23 & 40 & & \\
\hline & & $\%$ & 22,1 & 22,5 & & \\
\hline & \multirow{2}{*}{$\% 41$ ve üzeri } & $\mathrm{n}$ & 64 & 103 & & \\
\hline & & $\%$ & 61,5 & 57,9 & & \\
\hline
\end{tabular}

Yapılan ki-kare analizine göre kullanılan muhasebe programı ile basit usul defter oranı arasında ilişki bulunmaktadır $(p<0,05)$. Buna göre masaüstü uygulama tabanlı muhasebe programını kullananların çoğunluğunun $(\% 78,8)$ ve Web tabanlı muhasebe programını kullananların çoğunluğunun $(\% 83,8)$ basit usuldeki defter oranının toplam defterler içindeki oranı 0- 
\%20'dir. Oranın yüksek ve 0-\%20 çıkmasının nedeni ankete katılan SMMM'lerin yaklaşık \%82'sinin basit usuldeki defter oranının 0-\%20 olmasından kaynaklandığı söylenebilir (Tablo 2). Diğer taraftan işletme ve bilanço esası defter oranı ile kullanılan muhasebe programı arasında ilişki bulunmamaktadır $(p>0,05)$.

Tablo 9: Kullanılan Muhasebe Programı ile Bilanço Esasına Göre Tutulan Defterlerin İşletme Büyüklüğüne Göre Oranları Arasındaki ilişsi

\begin{tabular}{|c|c|c|c|c|c|c|}
\hline & & & \multicolumn{2}{|c|}{ Kullanılan Muhasebe Programı } & \multirow[b]{2}{*}{ Ki-kare } & \multirow[b]{2}{*}{$\mathrm{p}$} \\
\hline & & & Masaüstü uygulama & $\begin{array}{c}\text { Web Tabanlı } \\
\text { Uygulama }\end{array}$ & & \\
\hline \multirow{6}{*}{ Mikro Ölçekli İşletme Oranı } & \multirow{2}{*}{$0-\% 20$} & $\mathrm{~N}$ & 35 & 59 & \multirow{6}{*}{3,708} & \multirow{6}{*}{157} \\
\hline & & $\%$ & 33,0 & 35,5 & & \\
\hline & 0 & $\mathrm{~N}$ & 13 & 33 & & \\
\hline & $10<1-40$ & $\%$ & 12,3 & 19,9 & & \\
\hline & \multirow{2}{*}{$\% 41$ ve üzeri } & $\mathrm{N}$ & 58 & 74 & & \\
\hline & & $\%$ & 54,7 & 44,6 & & \\
\hline \multirow{6}{*}{$\begin{array}{l}\text { Küçük Ölçekli Iş̧letme Defter } \\
\text { Oranı }\end{array}$} & \multirow{2}{*}{$0-\% 20$} & $\mathrm{~N}$ & 42 & 60 & \multirow{6}{*}{2,325} & \multirow{6}{*}{, 313} \\
\hline & & $\%$ & 48,3 & 41,7 & & \\
\hline & $021-40$ & $\mathrm{~N}$ & 10 & 27 & & \\
\hline & $10 \angle 1-40$ & $\%$ & 11,5 & 18,8 & & \\
\hline & \multirow{2}{*}{$\% 41$ ve üzeri } & $\mathrm{N}$ & 35 & 57 & & \\
\hline & & $\%$ & 40,2 & 39,6 & & \\
\hline \multirow{6}{*}{$\begin{array}{l}\text { Orta Ölçekli İşletmeDefter } \\
\text { Oranı }\end{array}$} & \multirow{2}{*}{$0-\% 20$} & $\mathrm{~N}$ & 40 & 61 & \multirow{6}{*}{1,247} & \multirow{6}{*}{, 536} \\
\hline & & $\%$ & 56,3 & 55,0 & & \\
\hline & & $\mathrm{N}$ & 11 & 24 & & \\
\hline & \%21-40 & $\%$ & 15,5 & 21,6 & & \\
\hline & \multirow{2}{*}{$\% 41$ ve üzeri } & $\mathrm{N}$ & 20 & 26 & & \\
\hline & & $\%$ & 28,2 & 23,4 & & \\
\hline
\end{tabular}

Yapılan ki-kare analizine göre kullanılan muhasebe programı ile tutulan defterlerin işletme büyüklükleri arasında ilişki bulunmamaktadır $(p>0,05)$

SMMM'lerin web tabanlı muhasebe programını tercih etme nedenlerinin önem ortalamaları Tablo $10^{\prime}$ da verilmektedir.

Tablo 10: Web Tabanlı (Bulut) Muhasebe Programını Tercih Etme Nedenleri

\begin{tabular}{lcc}
\hline Verilerin Güvende Tutulması Ve Arşivlenmesi & $\mathrm{n}$ & Ortalama \\
Her Yerden Erişebilme & 156 & 4,51 \\
Bilgileri Güncellemeye Gerek Yok & 156 & 4,45 \\
Kullanım Kolaylı̆̆ı & 154 & 4,44 \\
Yazılımları Bakım, Güncelleme Satın Almaya Gerek Yok & 152 & 4,38 \\
Muhasebe İşlerinin Kolaylaştırıyor & 153 & 4,35 \\
İsgücü Maliyetlerini Azaltması & 154 & 4,34 \\
Zaman Tasarrufu Sağlayarak Mükelleflere Sunulan Hizmetin Çeşitlendirmesini & 153 & 4,24 \\
Sağlamak & 152 & 4,23 \\
Donanım Bakım Maliyeti Azalması & 154 & 4,21 \\
Anında Sorun Çözme Ve Eğitim & 149 & 4,17 \\
Sistemin Esnek Olması & 154 & 4,10 \\
Hazır Şablonlar Kullanarak Özel Raporlar Üretmesi & 152 & 4,09 \\
\hline
\end{tabular}




\begin{tabular}{lcc}
\hline Mükelleflerle Daha Fazla İşbirliği Yapmayı Sağlıyor & 154 & 4,01 \\
Gelir Artışı Sağlaması & 153 & 3,76 \\
Mükellefin İsteği Üzerine Kullanım & 153 & 3,33 \\
\hline
\end{tabular}

SMMM'lerin web tabanlı muhasebe programı kullanmayı tercih etme nedenleri incelendiğinde, önem ortalaması en yüksek olan üç faktör sırasıyla "verilerin güvende tutulması ve arşivlenmesi", "her yerden erişebilme" ve "bilgileri güncellemeye gerek olmaması"dır. En düşük önem ortalamasına sahip faktör ise "mükellefin isteği üzerine kullanım"dır.

Web tabanlı muhasebe programı kullanmayan SMMM'lerin uygulamayı tercih etmeme nedenlerinin önem ortalamaları Tablo 11 'de verilmiştir. Soruya web tabanlı muhasebe programı kullanan SMMM'ler de cevap verdiklerinden dolayı ilişki analizi de yapılmıştır ve önemli bir bulgu çıkmasına neden olmuştur.

Tablo 11: Web Tabanlı (Bulut) Muhasebe Programı Tercih Etmeme Nedenleri

\begin{tabular}{|c|c|c|c|c|c|c|}
\hline & & $\mathrm{n}$ & Ortalama & ss & $\mathrm{T}$ & $P$ \\
\hline \multirow{2}{*}{$\begin{array}{l}\text { Mevcut Programdan } \\
\text { Memnunum/Ihtiyacım Yok }\end{array}$} & Masaüstü Uygulama & 84 & 4,50 & 0,78 & \multirow{2}{*}{3,843} & \multirow{2}{*}{,000 } \\
\hline & Web Tabanlı Uygulama & 69 & 3,81 & 1,40 & & \\
\hline \multirow{2}{*}{$\begin{array}{l}\text { Bulut Sistemini Tanımıyorum/Bilgi } \\
\text { Sahibi Değilim }\end{array}$} & Masaüstü Uygulama & 80 & 3,84 & 1,11 & \multirow{2}{*}{1,841} & \multirow{2}{*}{,068 } \\
\hline & Web Tabanlı Uygulama & 66 & 3,45 & 1,41 & & \\
\hline \multirow{2}{*}{ Fayda Sağladığını Düşünmüyorum } & Masaüstü Uygulama & 78 & 3,53 & 1,05 & \multirow{2}{*}{2,772} & \multirow{2}{*}{,006 } \\
\hline & Web Tabanlı Uygulama & 65 & 2,98 & 1,28 & & \\
\hline \multirow{2}{*}{$\begin{array}{l}\text { Gelecekte Popüler Olacağına } \\
\text { İnanmıyorum }\end{array}$} & Masaüstü Uygulama & 76 & 3,47 & 1,11 & \multirow{2}{*}{1,771} & \multirow{2}{*}{079} \\
\hline & Web Tabanlı Uygulama & 66 & 3,12 & 1,26 & & \\
\hline \multirow{2}{*}{$\begin{array}{l}\text { Veri Güvenliğinin Ve Gizliliğinin } \\
\text { Zayıf Olması }\end{array}$} & Masaüstü Uygulama & 78 & 3,88 & 1,07 & \multirow{2}{*}{3,070} & \multirow{2}{*}{,003 } \\
\hline & Web Tabanlı Uygulama & 66 & 3,24 & 1,44 & & \\
\hline \multirow{2}{*}{ Kötü İnternet Bağlantısı } & Masaüstü Uygulama & 76 & 3,62 & 1,18 & \multirow{2}{*}{2,024} & \multirow{2}{*}{,045 } \\
\hline & Web Tabanlı Uygulama & 63 & 3,17 & 1,41 & & \\
\hline \multirow{2}{*}{$\begin{array}{l}\text { Muhasebe Uygulamaları Üzerinde } \\
\text { Kontrol Sahibi Olamama }\end{array}$} & Masaüstü Uygulama & 75 & 3,67 & 1,15 & \multirow{2}{*}{1,838} & \multirow{2}{*}{,068 } \\
\hline & Web Tabanlı Uygulama & 63 & 3,27 & 1,38 & & \\
\hline \multirow{2}{*}{$\begin{array}{l}\text { Hizmeti Sunan İşletmelerin Verdiği } \\
\text { Hizmetin Kesintiye Uğraması }\end{array}$} & Masaüstü Uygulama & 73 & 3,77 & 1,06 & \multirow{2}{*}{2,118} & \multirow{2}{*}{,036 } \\
\hline & Web Tabanlı Uygulama & 65 & 3,34 & 1,31 & & \\
\hline
\end{tabular}

Ankete katılan SMMM'lere web tabanlı muhasebe programını tercih etmeme nedenleri sorulduğunda, bulut muhasebe programı kullanan SMMM'lerin önemli sayılabilecek bir kısmı da bu bölümü cevaplandırmıştır. Bu da SMMM'lerin kullandıkları web tabanlı muhasebe programının bulut tabanlı çalıştığının farkında olmaması ve BB hakkında bilgi sahibi olmadığı sonucunun çıkarılmasını sağlamaktadır. Bu çıkarımı Tablo 12 ve 13'de desteklemektedir.

Masaüstü muhasebe uygulaması kullanan SMMM'lerin web tabanlı muhasebe uygulamasını tercih etmemesinin en önemli nedeni "mevcut programdan memnun olması/ihtiyacı olmaması"dır. Diğer önemli faktörler ise "bilgi sahibi olmaması/bulut sistemini tanımaması" ve "veri güvenliğinin ve gizliliğinin zayıf olması"dır.

Tablo 12: Kullanılan Muhasebe Programı ile Gelecek 3 Yıl Içinde Muhasebe Programı Kullanmayı Planlama Durumu Arasındaki ilişki

\begin{tabular}{|c|c|c|c|c|c|c|}
\hline & & & \multicolumn{2}{|c|}{ Kullanılan Muhasebe Programı } & \multirow[b]{2}{*}{ Ki-kare } & \multirow[b]{2}{*}{$\mathrm{P}$} \\
\hline & & & Masaüstü Uygulama & $\begin{array}{l}\text { Web Tabanlı } \\
\text { Uygulama }\end{array}$ & & \\
\hline \multirow{4}{*}{$\begin{array}{l}\text { Gelecek } 3 \text { Yıl İçinde Web Tabanlı (Bulut) } \\
\text { Muhasebe Programı Kullanma Planı }\end{array}$} & evet & $\mathrm{n}$ & 29 & 62 & \multirow{4}{*}{5,584} & \multirow{4}{*}{,018 } \\
\hline & & $\%$ & $30,2 \%$ & $45,6 \%$ & & \\
\hline & \multirow{2}{*}{ hayır } & $\mathrm{n}$ & 67 & 74 & & \\
\hline & & $\%$ & 69,8 & 54,4 & & \\
\hline
\end{tabular}


Masaüstü muhasebe programı kullanan SMMM'lerin yaklaşık \%70'i gelecek 3 yıl içinde bulut tabanlı muhasebe programına geçmeyi düşünmediğini belirtmiştir. Yapılan ki-kare analizine göre kullanılan muhasebe programı ile gelecek 3 yıl içinde muhasebe programı kullanmayı planlama durumu arasında ilişki bulunmaktadır $(p<0,05)$. Buna göre masaüstü uygulama tabanlı muhasebe programını kullananların çoğunluğunun $(\% 69,8)$ ve web tabanlı muhasebe programını kullananların çoğunluğunun $(\% 54,4)$ böyle bir düşüncesi bulunmamaktadır. Bu tablonun bulgularına göre de gerek masaüstü kullanıcılarının gerekse de web tabanlı kullanıcıların BB ile ilgili bir farkındalığa sahip olmadığı söylenebilir.

Masaüstü muhasebe uygulaması kullanan SMMM'lerin web tabanlı muhasebe uygulamasına geçiş planı ve ilişki analizi Tablo 13'te verilmektedir.

Tablo 13: Kullanılan Muhasebe Programı ile Mükellefin İsteğine Göre Web Tabanlı Muhasebe Programı Kullanma Arasındaki ilişki

\begin{tabular}{|c|c|c|c|c|c|c|}
\hline & & & \multicolumn{2}{|c|}{ Kullanılan Muhasebe Programı } & \multirow[b]{2}{*}{ Ki-kare } & \multirow[b]{2}{*}{$P$} \\
\hline & & & $\begin{array}{l}\text { Masaüstü } \\
\text { Uygulama }\end{array}$ & $\begin{array}{c}\text { Web Tabanlı } \\
\text { Uygulama }\end{array}$ & & \\
\hline \multirow{4}{*}{$\begin{array}{l}\text { Mükellef Bulut Tabanlı } \\
\text { Muhasebe Programı } \\
\text { Kullanmasını İsterse }\end{array}$} & & $\mathrm{n}$ & 58 & 98 & \multirow{4}{*}{2,289} & \multirow{4}{*}{ 130 } \\
\hline & tavsıyesıne uyarım & $\%$ & 58,6 & 68,1 & & \\
\hline & \multirow{2}{*}{$\begin{array}{l}\text { defterini tutmayı } \\
\text { bırakırım }\end{array}$} & $\mathrm{n}$ & 41 & 46 & & \\
\hline & & $\%$ & 41,4 & 31,9 & & \\
\hline
\end{tabular}

Tablo 13 incelendiğinde web tabanlı muhasebe programını tercih etmeyen SMMM'lerin mükelleflerinin istemesi durumunda programlarını değiştirip değiştirmeyecekleri sorulduğunda her iki grubun da cevaplandırdığı görülmektedir. Aynı şekilde web tabanlı muhasebe programı kullanan SMMM'lerin, kullandıkları programın bulut tabanlı olduğunu bilmedikleri söylenebilir.

Kullanılan muhasebe programlarının mobil uygulamaları kullanım sıklığı açısından karşılaştırıması (t testi) Tablo $15^{\prime}$ te yer almaktadır.

Tablo 15: Kullanılan Muhasebe Programları ile Mobil Uygulamaları Kullanım Sıklığı Arasındaki Karşılaştırma

\begin{tabular}{lllcccc}
\hline & & $\mathrm{n}$ & Ortalama & $\mathrm{ss}$ & $\mathrm{T}$ & $\mathrm{P}$ \\
\hline \multirow{2}{*}{ Belge Gönderme/Alma } & Masaüstü uygulama & 108 & 3,62 & 0,72 & \multirow{2}{*}{$, 1,684$} &, 093 \\
& Web Tabanlı Uygulama & 176 & 3,76 & 0,62 & & \multirow{2}{*}{093} \\
\hline \multirow{2}{*}{$\begin{array}{l}\text { Mükelleflerin Vergi ve SGK } \\
\text { İ̧lemleri }\end{array}$} & Masaüstü uygulama & 107 & 3,48 & 0,82 & $-1,687$ & \multirow{2}{*}{, 153} \\
\hline \multirow{2}{*}{$\begin{array}{l}\text { Muhasebe Veri Girişi ve Rapor } \\
\text { Alma }\end{array}$} & Web Tabanlı Uygulama & 174 & 3,63 & 0,71 & & $-1,432$ \\
\hline
\end{tabular}

Masaüstü uygulama ile web tabanlı muhasebe programı kullananlar arasında mobil uygulamaların kullanım sıklığı açısından istatistiksel olarak anlamlı farklılık bulunmamaktadır. Tablo incelendiğinde web tabanlı muhasebe uygulaması kullanan SMMM'lerin mobil uygulamaları kullanma sıklığı ortalaması daha yüksektir.

\section{SONUÇ}

Bu çalışmada SMMM'lerin web (bulut) tabanlı muhasebe uygulamalarını benimseme ve farkındalık düzeyleri tespit edilmeye çalışılmıştır. Çalışmanın diğer çalışmalardan farkıılı̆ı, kullanılan muhasebe programlarının demografik ve mesleki bilgilere göre de ilişki analizlerinin yapılmasıdır. Çalışmadan elde edilen önemli bulgular ve yorumları aşağıdaki gibidir:

- Ankete katılan SMMM'lerin yarısından fazlası web tabanlı muhasebe programını kullanmaktadır. Ancak Tablo 11, 12 ve 13 'ten elde edilen bulgulara göre web tabanlı muhasebe programı kullanan SMMM'ler, kullandıkları programın bulut tabanlı muhasebe programı olduğunun farkında değillerdir ve BB ile ilgili bir bilgiye sahip değillerdir.

- Web tabanlı muhasebe programı kullanan SMMM'lerin tamamı LUCA programını kullanmaktadır. SMMM'lerin LUCA muhasebe programını tercih etme nedeni olarak, programın muhasebecilerin en üst birliği olan TÜRMOB tarafından geliştirilmiş olması ve meslek odalarının destek olmasının etkili olduğu, ayrıca web tabanlı muhasebe yazılımına yönelik yaygın olan veri gizliliği ve güvenliği konusundaki endişeyi azalttığı söylenebilir. 
- $\quad$ ilişki analizleri bulgularına göre, kullanılan program ile yaş arasında ilişki bulunmamakla birlikte, web tabanlı muhasebe programını kullanmayı tercih eden SMMM'lerin genç ve orta yaş grubu olduğu görülmektedir. Mesleki faaliyet sürelerine göre anlamlı bir fark çıkmıştır. Buna göre hem masaüstü program kullananlar hem de web tabanlı muhasebe programı kullananların faaliyet süreleri 10 yıl ve altıdır. İki grubun da 10 yıl ve altı çıkması, ankete cevap veren SMMM'lerin önemli bir oranının mesleki faaliyet sürelerinin 10 yıl ve altı olmasından kaynaklandığı söylenebilir. Web tabanlı muhasebe programı kullananların çoğunluğunun mesleki faaliyet süresi 0-15 yıl aralığındadır. Bu da genç ve orta yaş grubunda tercih edilme durumunu desteklemektedir. Yine tutulan defter türleri ve kullanılan muhasebe programı arasındaki ilişki incelendiğinde sadece basit usul oranı toplam defter türleri içindeki oranı 0-\%20 arasında olan masaüstü kullanııılar ve web tabanlı kullanıcılar de defter oranı arasında farklııı çıkmıştır. Mesleki faaliyet süresinde olduğu gibi her iki grubunda 0-\%20 oranında olan SMMM olması, katılımcıların \%82'nin çok az sayıda basit usulde defter türünün olmasından kaynaklanmaktadır. İşletme esası defter oranı, bilanço esası defter oranı ve işletme büyüklüklerine göre kullanılan muhasebe programı arasında ilişki bulunmamaktadır. Son olarak mevcut programın kullanılma süresi ile muhasebe programları arasındaki ilişki analizinde, masaüstü program kullananların 5-7 yıl aralığında, web tabanlı muhasebe programı kullananların \%37,2 'si 4 yıl ve altı olarak çıkmıştır.

- Web tabanlı muhasebe programı kullanan SMMM'lerin tercih nedenleri arasında önem ortalaması en yüksek olan faktörler sırasıyla "verilerin güvende tutulması ve arşivlenmesi", "her yerden erişebilme" ve "bilgileri güncellemeye gerek olmaması" dır. En düşük önem ortalamasına sahip faktör ise "mükellefin isteği üzerine" kullanımdır.

- Masaüstü muhasebe programı kullanan SMMM'lerin web tabanlı muhasebe programını tercih etmemesinin önem ortalaması en yüksek olan faktörler, "mevcut programdan memnun olması/ihtiyacı olmaması", "bilgi sahibi olmaması/bulut sistemeni tanımaması" ve "veri güvenliğinin ve gizliliğinin zayıf olması" dır. Mevcut programdan memnun olanların yaş ortalaması yüksek olan SMMM'ler olduğu söylenebilir. Tercih etmeyenlerin gelecek 3 yıl içinde buluta geçiş yapmayı düşünüp düşünmedikleri sorulduğunda yaklaşık \%70'i hayır cevabını vermiştir. Çoğunluğun hayır cevabını vermesi tercih etmeme nedenleri ile ilişkilidir. Masaüstü program kullanaların da farkındalığa sahip olmadığı sonucu çıkarılabilir. Masaüstü programdan vazgeçmese de mükelelflerinin istemesi durumunda buluta geçiş yapabileceğini belirten SMMM'lerin oranı yaklaşık \%59'dur.

- Kullanılan muhasebe programları ile mobil uygulamaları kullanım sıklığı karşılaştııılığında web tabanlı muhasebe programı kullanan SMMM'lerin sıklık ortalaması masaüstü kullanıcılara göre yüksek olsa da yeterli büyüklükte olmadığı söylenebilir.

SMMM'lerin web tabanlı muhasebe programını daha iyi tanımaları ve bilmeleri için hizmet sağlayıcıların bulut tabanlı programların sunduğu hizmetler ve kullanımı ile ilgili bilgilendirmeler yapması gerekmektedir. Aynı zamanda meslek odaları ve üniversitelerin de ilgili birimleri tarafından seminerler, toplantılar düzenlenerek farkındalık düzeyinin arttırıması sağlanabilir. Geleceğin iş düzeni artık dijital ortamlarda gerçekleşecektir. Teknolojiyi zamanında benimseyen ve uyum sağlayan SMMM'lerin bu ortamdan kazançlı çıkacağı konusunda şüphe yoktur. SMMM'ler, BB'nin getirdiği yeniliklerden faydalanarak yeni hizmetler sunup mükelleflerin sadakatini arttırabilir. Nitekim BB tüm iş dünyasını etkileyecek teknolojidir. İşletmelerin de iş uygulamalarında BB'ye geçiş yapması zamanla SMMM'lerden beklenen hizmetlerin farklılaşmasına neden olacaktır. Dolayısıyla SMMM'ler için BB'ye geçiş bir istek değil zorunluluk olacaktır.

Bu çalışma, elde edilen bulguların faydası açısından literatüre katkı sağlamaktadır. Ancak anket uygulamasının sadece Antalya merkez ilçeleri kapsaması çalışmanın kısıtını oluşturmaktadır. Sonuçların Türkiye genellemesini oluşturması söz konusu değildir. Nitekim çalışmanın ekonominin daha dinamik ve kurumsal işletmelerin daha yoğun olduğu yerlerde (isstanbul ve İzmir gibi) yapılması SMMM'lerin yeni teknoloji kullanma eğilimleri daha çabuk/hızlı olabilir. Dolayısıyla bölgelere göre benimseme düzeyleri farklııı gösterebilir. İleriki çalışmalar için Türkiye'nin farklı coğrafi bölgelerinin hedef kitle olarak seçilmesi önerileribilir. 


\section{KAYNAKLAR}

AlCattan R. F., (2014). Integration of Cloud Computing and Web2.0 Collaboration Technologies in E-Learning, International Journal of Computer Trends and Technology (IJCTT) - volume 12, number 1, p.46-55.

Angeles, S. (2017). Choosing the Right Small Business Accounting Software, http://www.businessnewsdaily.com/7542-choosingaccounting-software.html

Aytekin, A., Erdoğan, Y., Kavalcı, K., (2016). YENi BíR iş MODELi: MUHASEBE ALANINDA BULUT BíLişiM, Uluslararası Yönetim İktisat ve İşletme Dergisi, ICAFR 16 Özel Sayısı, s.46-62

Blake, G., (2012). How The Acconting Industry Is Being Changed By Cloud Computing, https://cloudtweaks.com/2012/02/how-theaccounting-industry-is-being-changed-by-cloud-computing/

Borschowa, J., (2016). 4 Key Trends Shaping the Transformation of the Accounting Industry, https://www.firmofthefuture.com/content/4key-trends-shaping-the-transformation-of-the-accounting-industry/

Brinda, M., Heric, M., (2017), The Changing Faces of the Cloud, http://www.bain.com/publications/articles/the-changing-faces-of-thecloud.aspx

Business Software Allianc e,(2013). Country Report: Turkey,

http://cloudscorecard.bsa.org/2012/assets/PDFs/country_reports/Country_Report_Turkey_en.pdf

$\mathrm{CCH}$ Wolters Kluwer business, (2013). Cloud computing - a matter of survival for the accounting industry? A national research study commissioned by CCH April 2013, p.3-11.

Chou, D., (2015). Cloud computing: A value creation model, Computer Standards \& Interfaces, Volume 38, February 2015, p.72-77

Cloud Accounting Institute (2014). Cloud Accountıng Solutıons Best Practıces 2014 Benchmark Study, http://www.trustantial.com/wpcontent/uploads/2014/11/Cloud-Solutions-Best-Practices-2014-Benchmark-Study.pdf

Defelice, A., (2010). Cloud Computing: What Accountants Need to Know, http://www.journalofaccountancy.com/issues/2010/oct/20102519.html

Dimitriu, O., Matei, M., (2014). A New Paradigm for Accounting through Cloud Computing, Procedia Economics and Finance 15 ( 2014 ), p. $840-846$.

Du, H., Cong, Y., (2010). Cloud Computing, Accounting, Auditing, and Beyond, The CPA Journal, October 2010, p.60-69.

Fox, B., (2012). Cloud computing a "game-changer" for EU economy, Kroes says, https://euobserver.com/news/117695.

Gahlaut, D., (2016). Top 7 Benefits of Cloud Computing for CPA Firms, https://www.slideshare.net/DeepanshuGahlaut92/top-7-benefitsof-cloud-computing-for-cpa-firms

Geczy, P., Izumi, N., Hasida, K., (2012). Cloudsourcing: Managing Cloud Adoption. Global Journal of Business Research, 6, p.57-70.

Göbel, R., (2015). Şirketler bulut bilişimin farkına varıyor, http://www.bthaber.com/kobi-ler-icin-rekabet-araclari/sirketler-bulut-bilisiminfarkina-variyor/1/16577

Guptaa, P., Seetharamana,A., Raj, J.R., (2013). The usage and adoption of cloud computing by small and medium businesses, International Journal of Information Management 33 (2013),p. 861-874.

Huber, N., (2016). What does cloud computing mean for accountancy?, https://www.icas.com/ca-today-news/what-does-cloudcomputing-mean-for-the-accountancy-profession

Kalkınma Bakanlığı Bilgi Toplumu Dairesi Başkanlığı, (2014). 2015-2018 Bilgi Toplumu Stratejisi ve Eylem Planı, Ankara

Kinsella, K., (2017). How Cloud Computing Can Benefit Accountants, http://www.cpaireland.ie/your-business/businessresource/technology/how-cloud-computing-can-benefit-accountants

Lim, F.P.C., (2013). Impact of Information Technology on Accounting Systems, Asia-pacific Journal of Multimedia Services Convergent with Art, Humanities, and Sociology Vol.3, No.2, December (2013), pp. 93-106 http://dx.doi.org/10.14257/AJMAHS.2013.12.02 ISSN: 2383-5281 AJMAHS Copyright C2013 SERSC 93.

Matthews, K., (2016). The Cloud Is Fueling The Tech Sector's Profits, https://cloudtweaks.com/2016/08/cloud-fueling-tech-sectors-profits/

Mell, P., Grance, T., (2011).'The NIST Definition of Cloud Computing'. National Institute of Standards and Technology, Special Publication 800-145, 2011.

Öz,Y., (2016)). Bulut Bilişim (Cloud Computing) ve Muhasebe, Bartın Üniversitesi i.i..B.F. Dergisi, Yıl:2016 Cilt:7 Sayı:13, s.63-79.

Pazowski, P., Pastuszak, Z., (2013). Cloud Computing - A Case Study For The New Ideal Of The Is/It Implementation, Management, Knowledge and Learning, International Conference, 2013, Zadar, Croatia, p.855-862. 
Randolph, J.P., Leslie, G., Tankersley, B., (2016). Accounting Firm Operations and Technology Survey, file:///C:/Documents\%20and\%20Settings/abcs/Belgelerim/Downloads/31PREVIEW-AFOT-2016-Complete-Survey-Results-eBook-v160621160627-4\%20(2).pdf

Sheinis, R., Ference, S.B., (2014). Data Security Risk: You Can Take It Anywhere, Journal of Accountancy April 2014, p.16-17.

Shkurti, R., Muça, E., (2014). An Analysıs Of Cloud Computıng and Its Role In Accountıng Industry ın Albanıa, Journal of Information Systems \& Operations Management;Dec2014, Vol. 8 Issue 2, p.1-12.

Stamford, C., (2016). Gartner Says by 2020 "Cloud Shift" Will Affect More Than \$1 Trillion in IT Spending, http://www.gartner.com/newsroom/id/3384720

Strauss, E., Kristandl, G., Quinn, M., (2016). The effects of cloud technology on management accounting and decision making, CIMA Research executive summary series, Volume 10 Issue 6.

Tarmidia, M., Rasid, S.Z.A., Alrazia, B., Roni, R.A., (2014). Cloud computing awareness and adoption among accounting practitioners in Malaysia, Procedia - Social and Behavioral Sciences 164 ( 2014 ), p. $569-574$.

Techtarget Network (2016). cloud computing, http://searchcloudcomputing.techtarget.com/definition/cloud-computing

Yigitbasioglu, O,M., (2015). External auditors' perceptions of cloud computing adoption in Australia, International Journal of Accounting Information Systems 18 (2015), p. 46-62. 